OPEN ACCESS

Edited by:

Nurit Hollander,

Tel Aviv University, Israel

Reviewed by:

Xiubao Ren,

Tianjin Medical University Cancer Institute and Hospital, China

Maria Raffaella Zocchi,

San Raffaele Scientific Institute

(IRCCS), Italy

*Correspondence:

Yufa Sun

dafa20136725@163.com

${ }^{t}$ These authors have contributed equally to this work

Specialty section:

This article was submitted to Cancer Immunity and Immunotherapy,

a section of the journal

Frontiers in Immunology

Received: 13 July 2020 Accepted: 02 October 2020 Published: 22 October 2020

Citation:

Shang J, Zha H and Sun Y (2020)

Phenotypes, Functions, and Clinical Relevance of Regulatory B Cells in Cancer.

Front. Immunol. 11:582657. doi: 10.3389/fimmu.2020.582657

\section{Phenotypes, Functions, and Clinical Relevance of Regulatory B Cells in Cancer}

\author{
Jin Shang ${ }^{1 \dagger}$, Haoran $\mathrm{Zha}^{2 \dagger}$ and Yufa Sun ${ }^{1 *}$ \\ ${ }^{1}$ Department of Health Service, Guard Bureau of the Joint Staff Department, Central Military Commission of PLA, \\ Beijing, China, 2 Department of Oncology, PLA Rocket Force Characteristic Medical Center, Beijing, China
}

In immune system, B cells are classically positive modulators that regulate inflammation and immune responses. Regulatory B cells (Bregs) are a subset of B cells which play crucial roles in various conditions, including infection, allergies, autoimmune diseases, transplantation, and tumors. Until now, unequivocal surface markers for Bregs still lack consensus, although numerous Breg subsets have been identified. Generally, Bregs exert their immunoregulatory functions mainly through cytokine secretion and intercellular contact. In the tumor microenvironment, Bregs suppress effector $\mathrm{T}$ cells, induce regulatory $T$ cells and target other tumor-infiltrating immune cells, such as myeloidderived suppressor cells, natural killer cells and macrophages, to hamper anti-tumor immunity. Meanwhile, the cross-regulations between Bregs and tumor cells often result in tumor escape from immunosurveillance. In addition, accumulating evidence suggests that Bregs are closely associated with many clinicopathological factors of cancer patients and might be potential biomarkers for accessing patient survival. Thus, Bregs are potential therapeutic targets for future immunotherapy in cancer patients. In this review, we will discuss the phenotypes, functions, and clinical relevance of Bregs in cancer.

Keywords: regulatory B cell, tumor immunology, tumor microenvironment, cancer progression, immunotherapy

\section{INTRODUCTION}

In immune system, B cells are classically recognized as positive modulators to regulate inflammation and immune responses by releasing antibodies and activating $\mathrm{T}$ cells through antigen presentation (1-3). Generally, B cells produce antibodies which are a critical part of the host immunity against infection, that can neutralize pathogens, opsonize pathogens for subsequent phagocytosis and mediate antibody-dependent cellular cytotoxicity (4-6). Besides, B cells also act to suppress immune responses. Accumulating studies have revealed that an immunoregulatory subset of B cells exists and exerts multifaceted functions (7-10). In the 1970s, a suppressive subset of B cells was firstly hypothesized to exist and modulate immune responses, based on reports indicating that the depletion of B cells in splenocytes was correlated with increased severity and duration of delayed-type hypersensitivity in a guinea pig model $(11,12)$. In the 1980 s, it was reported that activated splenic $\mathrm{B}$ cells prompted $\mathrm{T}$ cells to differentiate into suppressor $\mathrm{T}$ cells following adoptive transfer into naïve recipient mice $(13,14)$, further supporting the concept of "suppressor B cells". The term "regulatory B cells" (Bregs) was firstly coined in 2002 by Mizoguchi and his colleagues 
(15). They demonstrated that the interleukin-10 (IL10)-producing $\mathrm{CD} \mathrm{d}^{+}$Bregs were induced in a chronic inflammatory environment and dampened the progression of intestinal inflammation by repressing inflammatory cascades associated with IL-1 upregulation and STAT3 activation. Thereafter, mounting evidence has uncovered the roles of Bregs in numerous diseases and conditions, such as infection (16), allergies (17), autoimmune diseases (18), transplantation (19), and tumors (20).

To support tumor progression, tumor cells usually generate a tumor microenvironment (TME), which comprises immune cells, fibroblasts, endothelial cells, and the extracellular matrix (ECM). Among the various tumor-infiltrating immune cells in the TME, Bregs release anti-inflammatory mediators and express inhibitory molecules to exert immunoregulatory functions and shape the tumor immune milieu (21-25). In this review, we will discuss the phenotypes, functions and clinical relevance of Bregs in cancer.

\section{PHENOTYPES AND IMMUNOREGULATORY FUNCTIONS OF BREGS}

Until now, the definition and classification of Bregs remain unclear due the lack of unique surface markers. As cell populations can be classified based on cytokine production (26), Breg cells are also classified according to their secreted cytokines in many cases and comprise an assortment of subsets (27). Moreover, the phenotypes of human Bregs are not identical to those of murine Bregs. Thus far, several human Breg subsets have been identified. Human $\mathrm{CD} 19^{+} \mathrm{CD} 25^{\mathrm{hi}}$ Bregs, which enhance Treg function, have been reported (28). IL-10-expressing $\mathrm{CD} 24^{+} \mathrm{CD} 38^{+}$Bregs were characterized in gastric cancer (GC) patients (29). IL-21-induced $\mathrm{CD}_{19}{ }^{+} \mathrm{CD} 38^{+} \mathrm{CD} 1 \mathrm{~d}^{+} \mathrm{IgM}^{+} \mathrm{CD} 147^{+}$Bregs, which express granzyme $\mathrm{B}(\mathrm{GrB})$, have also been identified in solid tumors (30). In addition, $\mathrm{CD} 19^{+} \mathrm{CD} 24^{+} \mathrm{CD} 38^{+}$Bregs were found in invasive breast carcinoma (IBCa) patients, and they were recognized in higher percentages in the breast tissue and peripheral blood of IBCa patients than those in benign tumors and healthy individuals (31). Similarly, well-founded evidence has also revealed several subsets of murine Bregs with different phenotypes. In a B16-F10 melanoma murine model, transitional 2 marginal zone precursor (T2-MZP) Bregs were identified with the $\mathrm{B} 220^{+} \mathrm{CD} 23^{+} \operatorname{IgM}^{\text {hi }} \mathrm{CD} 21^{\text {hi }}$ phenotype in tumor-draining lymph nodes (TDLNs) (32). In another study, splenic CD1d ${ }^{\text {hi }} \mathrm{CD}^{+}$Bregs sorted from wild-type (WT) and $\mathrm{CD} 20$-deficient mice were adoptively transferred into $\mathrm{Cd} 19^{-}$广 mice and CD20 monoclonal antibody (mAb)-treated mice, respectively, resulting in normalized contact hypersensitivity (33). Moreover, it has been determined that $\operatorname{IgM}^{\text {hi }} C D 1 d^{\text {hi }}$ $\mathrm{CD} 5^{+} \mathrm{CD} 19^{\text {hi }} \mathrm{CD} 23^{\text {low }} \mathrm{CD} 38^{\text {hi }} \mathrm{B} 220^{\text {hi }}$ Bregs could differentiate into $\mathrm{CD}_{138^{+}}$plasma cells, which secrete IgM and IgG antibodies (34). $\mathrm{CD} 39^{+} \mathrm{CD} 73^{+}$Bregs release adenosine and ameliorate the severity of dextran sulfate sodium salt (DSS)-induced acute colitis (35). Regarding tumor, the tumor-associated Breg phenotypes that have been reported to date are listed in Table $\mathbf{1}$.
Bregs have been reported to exert immunoregulatory functions mainly through cytokine secretion and intercellular contact. The most commonly studied cytokines produced by Bregs are IL-10, IL-35, and transforming growth factor (TGF)$\beta$. IL-10 has multitudinous inhibitory functions and has been widely recognized as an immunoregulatory factor in various chronic inflammatory diseases (54). B10 cells, which are IL-10producing Bregs, inhibit $\mathrm{CD}^{+}{ }^{+} \mathrm{T}$ cell proliferation and proinflammatory cytokine production by releasing IL-10 (55-57). During chronic hepatitis B virus (HBV) infection, Bregs repress $\mathrm{HBV}$-specific $\mathrm{CD}^{+} \mathrm{T}$ cell responses in an IL-10-dependent manner (58). Moreover, B10 cell-derived IL-10 impairs the functions of dendritic cells and macrophages by inducing tolerant phenotypes (59). Additionally, Bregs inhibit interferon- $\gamma($ IFN- $\gamma$ ) produced by NK cells through IL-10 (60). Analogous to IL-10, TGF- $\beta$ is another pivotal mediator secreted by Bregs to regulate immune responses, and it can induce the generation of regulatory $\mathrm{T}$ cells (Tregs) $(54,61)$. Additionally, TGF- $\beta$ produced by Bregs augments the expression of cytotoxic $\mathrm{T}$ lymphocyte associated antigen-4 (CTLA-4) and Foxp3 in Tregs (28). In non-obese diabetic mice, Bregs induce Th1 cell apoptosis and suppress the activities of antigen-presenting cells via TGF- $\beta$ secretion (62). In autoimmune and infectious diseases, Bregs produce IL-35, which is an IL-12 family member and a crucial negative modulator of T-cell immunity (63). IL-35 produced by Bregs promotes Treg proliferation and impairs Th17 responses to enhance immune tolerance (54). Intriguingly, IL-35 has been found to convert B cells into IL-35-producing Bregs, thus establishing a positive feedback loop (64).

Aside from cytokine secretion, Bregs regulate immune responses through intercellular contact, including ligandreceptor interactions such as CTLA-4/CD86, CD40/CD40L, and Fas/FasL. In a study by Aharon et al., a transwell system was used to demonstrate that intercellular contact is the major mechanism through which Bregs increase Foxp3 and CTLA4 expression on Tregs (28). CD28 and CTLA-4 are generally expressed by T cells and are both ligands for CD80/CD86 (65). In another study, Paul and colleagues observed that when cocultured with autologous $\mathrm{T}$ cells, $\mathrm{CD} 19^{+} \mathrm{CD} 24^{\mathrm{hi}} \mathrm{CD} 38^{\text {hi }}$ Bregs decreased the percentage of tumor necrosis factor (TNF)- $\alpha^{+}$ and IFN $-\gamma^{+} \mathrm{CD} 4^{+} \mathrm{T}$ cells, and blocking antibodies against CD80/CD86 partially reversed this suppression (66). Similarly, the simultaneous blockade of IL-10, CD80, and CD86 inhibited Bregs from suppressing IFN- $\gamma$ and TNF- $\alpha$ production by $\mathrm{CD}^{+} \mathrm{T}$ cells in rheumatoid arthritis patients (67). These results indicate that interactions between Bregs and T cells involving CD80/CD86 mediate the suppression of T cell immunity. The CD40/CD40L signaling pathway plays critical roles in establishing humoral responses and is involved in immune responses to tumors (68). Bregs also regulate effector $\mathrm{T}$ cells through CD40/CD40L to induce T cell death and inhibit $\mathrm{T}$ cell response to autoantigens (69). In addition, blocking the binding of CD40/CD40L between Bregs and CD4 ${ }^{+} \mathrm{T}$ cells in two different tumor models caused distinct immune responses in terms of Th1/Th2 differentiation and Treg induction (70). 
TABLE 1 | Phenotypes and characteristics of tumor-associated Bregs.

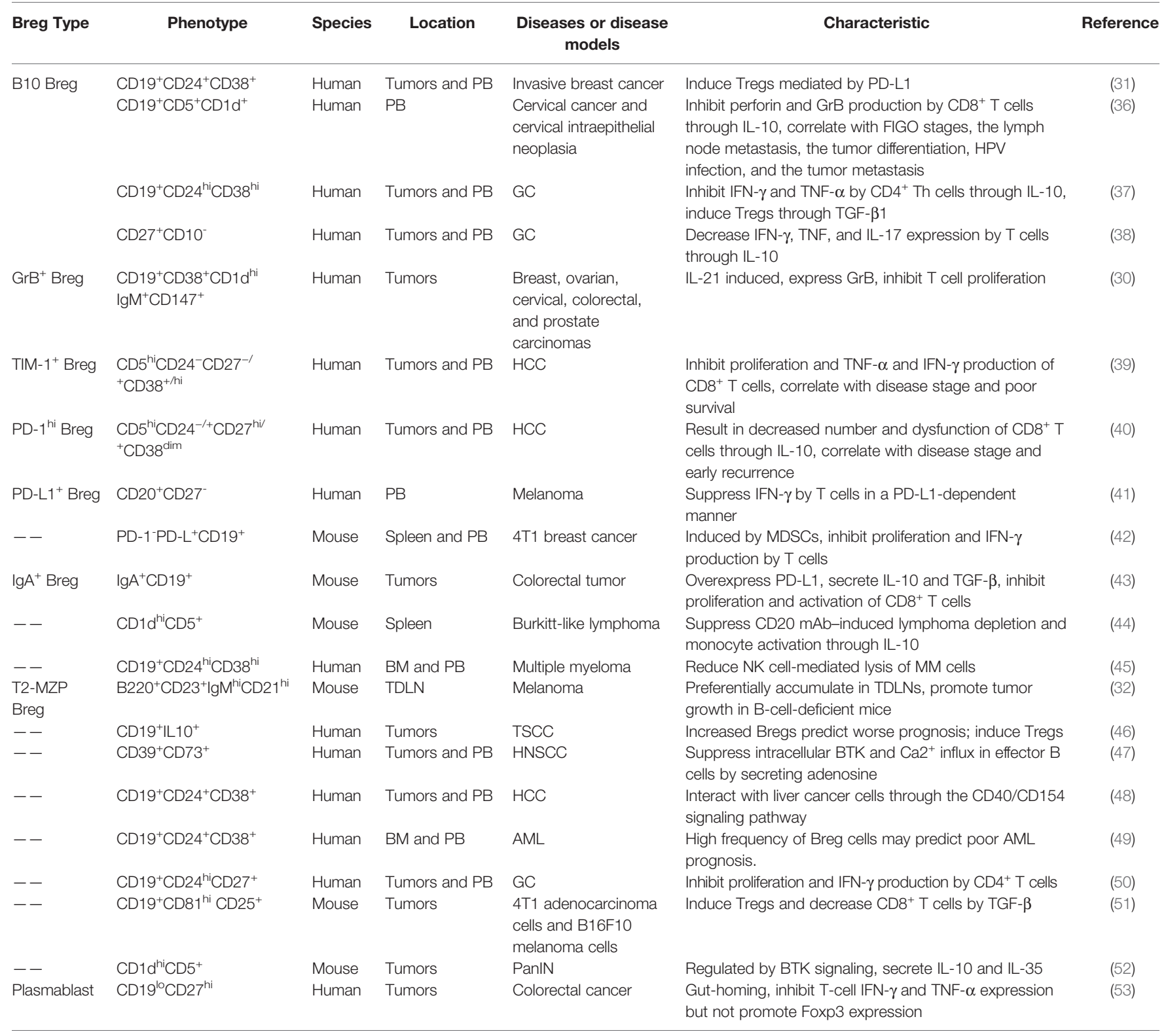

Breg, regulatory B cell; GrB, granzyme B; MDSC, myeloid-derived suppressor cell; MM, multiple myeloma; TDLN, tumor-draining lymph node; HNSCC, head and neck squamous cell carcinoma; HCC, hepatocellular carcinoma; HPV, human papillomavirus; TSCC, tongue squamous cell carcinoma; AML, acute myeloid leukemia; GC, gastric cancer; PB, peripheral blood; BM, bone marrow; BKT, Bruton's tyrosine kinase; PanIN, pancreatic intra-epithelial neoplasia.

Bregs have been reported to express FasL, which belongs to the TNF protein family and causes apoptosis by binding to its receptor, Fas (71). In the spleen, $\mathrm{CD}^{+}$Bregs express FasL and induce $\mathrm{T}$ cell apoptosis through the interactions of Fas/FasL (72). In another study, lipopolysaccharides-induced $\mathrm{CD}^{+} \mathrm{CD} 1 \mathrm{~d}^{\text {hi }}$ Bregs inhibited the proliferation of activated $\mathrm{CD}^{+} \mathrm{T}$ cells. After adding anti-FasL antibodies, the suppression of $\mathrm{CD}^{+} \mathrm{T}$ cell proliferation was partially reversed, suggesting Fas/FasL pathway-mediated regulation of Bregs (73). CD5 expression on Bregs should also be considered (74). In a B16 melanoma model, it was demonstrated that $\mathrm{CD}^{+} \mathrm{B}$ cells bound to IL- 6 directly through CD5 to promote tumor growth (75). These studies reveal that intercellular contact is critically important for Bregs to exert their immunoregulatory functions.

\section{MECHANISMS UNDERLYING BREG- MEDIATED REGULATION OF ANTITUMOR RESPONSES}

The immunoregulatory mechanisms of Bregs have gradually been elucidated in cancer. In the TME, the relationship between the host, tumor, and stroma is mediated by the balance of all tumor-infiltrating cells. Bregs interact with 
various tumor-infiltrating immune cells of the innate and adaptive immune systems to attenuate anti-tumor responses. Moreover, the cross-regulation between Bregs and tumor cells facilitates tumor progression (Figure 1; Table 2).

\section{Suppression of Effector T Cell Responses}

One of the many approaches by which Bregs modulate antitumor response is the direct inhibition of effector $\mathrm{T}$ cell responses. Lindner et al. found that IL-21-induced human $\mathrm{GrB}^{+}$ Bregs inhibited $\mathrm{CD} 4^{+} \mathrm{T}$-cell proliferation by transporting active GrB to $\mathrm{T}$ cells and degrading the $\mathrm{T}$-cell receptor $\zeta$-chain in vitro (30).Furthermore, these $\mathrm{GrB}^{+}$Bregs were found to infiltrate numerous human solid tumors, including breast, ovarian, cervical, colorectal, and prostate carcinomas. Subsequent in vivo functional assays should be conducted to validate the immunosuppressive properties of $\mathrm{GrB}^{+}$Bregs. In another in vitro co-culture system, Bregs sorted from cervical cancer patients secreted IL-10 to decrease the percentage of CD8 ${ }^{+}$ $\mathrm{T}$ cells, which produced perforin and GrB, whereas the addition of anti-IL-10 antibodies restored the level of these $\mathrm{CD}^{+} \mathrm{T}$ cells (36). Similarly, in ovarian cancer patients, B10 cells from ascites significantly lowered the frequency of autologous $\mathrm{CD}^{+} \mathrm{T}$ cells secreting IFN- $\gamma(80)$. In GC patients, depletion of Bregs from peripheral blood mononuclear cells resulted in increased frequencies of IFN $-\gamma^{+}$and TNF- $\alpha^{+} \mathrm{CD} 4^{+}$ $\mathrm{T}$ cells (37). Another study identified $\mathrm{CD} 27^{+} \mathrm{CD} 10^{-}$Bregs in both peripheral blood and tumor tissues of GC patients (38). Coculture of these $\mathrm{CD} 27^{+} \mathrm{CD} 10^{-} \mathrm{B}$ cells and autologous $\mathrm{T}$ cells showed that IL-10 secretion by $\mathrm{CD} 27^{+} \mathrm{CD} 10^{-} \mathrm{B}$ cells decreased IFN- $\gamma$, TNF and IL-17 production by $\mathrm{CD}^{+} \mathrm{T}$ cells and IFN- $\gamma$ and TNF production by $\mathrm{CD} 8^{+} \mathrm{T}$ cells. In addition, TGF- $\beta^{+}$Bregs induced by glioma cells inhibited the proliferation and release of perforin and $\mathrm{GrB}$ of $\mathrm{CD}^{+} \mathrm{T}$ cells (81). In human hepatocellular carcinoma (HCC), TIM- $1^{+}$Breg cells significantly suppressed the survival and TNF- $\alpha$ and IFN- $\gamma$ production of $\mathrm{CD}^{+}$effector T cells (39). Furthermore, Bregs harvested from the glioblastoma tissue of patients suppressed $\mathrm{CD}^{+} \mathrm{T}$ cell proliferation and the acquisition of an effector phenotype (82). Moreover, PD-L1 ${ }^{+}$ Bregs from stage II/III/IV melanoma patients impaired IFN- $\gamma$ production by $\mathrm{CD}^{+} \mathrm{T}$ cells in a PD-L1-dependent manner in a co-culture system (41). Another study by Xiao et al. demonstrated a novel protumorigenic $\mathrm{PD}-1^{\mathrm{hi}}$ Breg subset in human HCC (40). In corresponding tumor-bearing mice, these $\mathrm{PD}-1^{\text {hi }}$ Bregs mediated the reduction and dysfunction of $\mathrm{CD} 8^{+} \mathrm{T}$ cells after triggering $\mathrm{PD}-1$ in an IL-10-dependent manner. Moreover, Toll-like receptor-4-mediated upregulation of BCL6 was involved in inducing $\mathrm{PD}-1^{\mathrm{hi}}$ Breg in the HCC microenvironment. The $\mathrm{PD}-1 / \mathrm{PD}-\mathrm{L} 1$ signaling pathway in $\mathrm{T}$

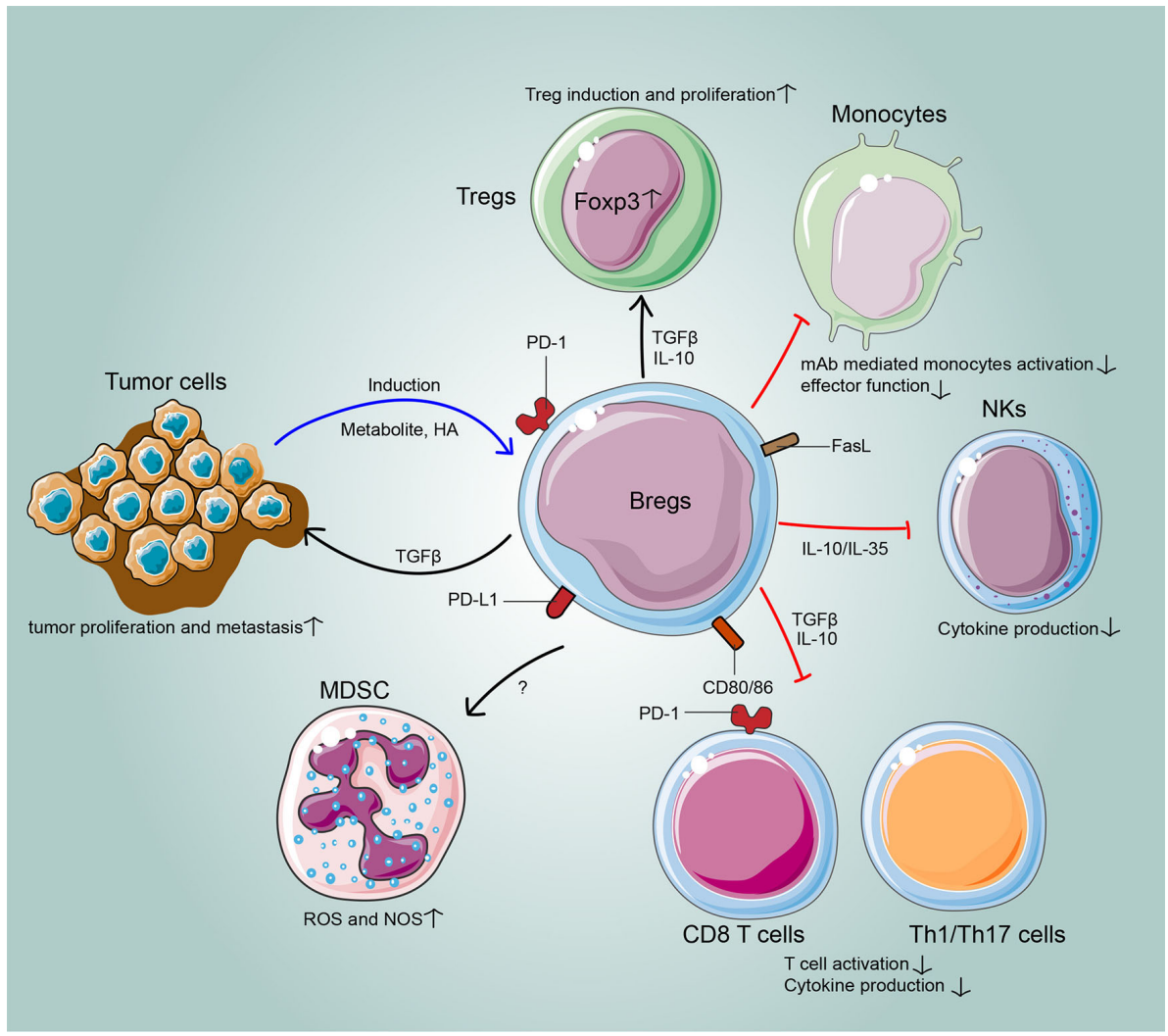

FIGURE 1 | The cross-regulation between Bregs and tumors. In the tumor microenvironment, Bregs suppress effector T cells, induce regulatory T cells and target other tumor-infiltrating immune cells, such as myeloid-derived suppressor cells, natural killer cells and macrophages, to hamper anti-tumor immunity. Meanwhile, the cross-regulations between Bregs and tumor cells often result in tumor escape from immunosurveillance. 
TABLE 2 | Targets of Bregs in tumor microenvironment to regulate antitumor responses.

\begin{tabular}{|c|c|c|c|}
\hline Targets & Cancer types & Mechanisms & References \\
\hline Effector T cells & $\begin{array}{l}\text { Breast, ovarian, cervical, colorectal, prostate, gastric } \\
\text { cancer; glioma, glioblastoma, melanoma, } \\
\text { hepatocellular carcinoma }\end{array}$ & Inhibit proliferation and cytokine production of effector T cells & $\begin{array}{l}(30,36-43,76- \\
79)\end{array}$ \\
\hline $\begin{array}{l}\text { Regulatory } \mathrm{T} \\
\text { cells }\end{array}$ & $\begin{array}{l}\text { Gastric, breast cancer; tongue squamous cell } \\
\text { carcinoma }\end{array}$ & Convert $\mathrm{CD} 4^{+} \mathrm{T}$ cells into Tregs & $(31,37,46,80)$ \\
\hline MDSCs & 4T1 adenocarcinoma cells and B16F10 melanoma & $\begin{array}{l}\text { Educate MDSCs to fully evoke regulatory and prometastatic functions of } \\
\text { MDSCs }\end{array}$ & $(81)$ \\
\hline \multirow[t]{2}{*}{ NK cells } & Mouse EL-4 tumor & Secrete IL-10 to inhibit IFN- $\gamma$ production and tumor elimination by NK cells & $(60)$ \\
\hline & Multiple myeloma & Abolish NK cell-mediated lysis of multiple myeloma cells & (45) \\
\hline Effector B cells & Head and neck squamous cell carcinoma & $\begin{array}{l}\text { Secrete adenosine to dampen BKT phosphorylation and } \mathrm{Ca}^{2+} \text { influx in } \\
\text { effector B cells }\end{array}$ & $(47)$ \\
\hline $\begin{array}{l}\text { Monocytes/ } \\
\text { macrophages }\end{array}$ & Lymphoma & $\begin{array}{l}\text { Secrete IL-10 to suppress mAb-mediated monocyte activation and effector } \\
\text { function, resulting in reduced lymphoma depletion }\end{array}$ & $(44)$ \\
\hline \multirow[t]{4}{*}{$\begin{array}{l}\text { Breg-tumor } \\
\text { cross-regulation }\end{array}$} & Hepatocellular carcinoma & $\begin{array}{l}\text { Bregs directly interacted with liver cancer cells to enhance cancer growth } \\
\text { and invasiveness. }\end{array}$ & $(48)$ \\
\hline & Multiple myeloma & Multiple myeloma cells inhibited apoptosis of Bregs. & $(45)$ \\
\hline & Breast cancer & $\begin{array}{l}\text { Breast cancer cells produced metabolites of the } 5 \text {-lipoxygenase pathway } \\
\text { to generate Bregs, leading to cancer escape eventually. }\end{array}$ & (82) \\
\hline & B16-F10 melanoma & $\begin{array}{l}\text { Bregs were restrictedly accumulated in TDLN, which promoted tumor } \\
\text { growth after adoptive transfer. }\end{array}$ & (32) \\
\hline
\end{tabular}

Treg, regulatory T cell; MDSC, myeloid-derived suppressor cell; NK, natural killer; BKT, Bruton's tyrosine kinase; TDLN, tumor-draining lymph node.

cells has been extensively explored, but its role in B cells has received less attention. This study reveals the inhibitory role of PD-1/PD-L1 signaling in Breg-mediated immunosuppression in HCC. Thus, the mechanism underlying clinical tumor regression achieved by anti-PD-1 and anti-PD-L1 antibodies might also involve blocking PD-1/PD-L1 signaling on Bregs.

In a murine breast cancer model, a novel PD- ${ }^{-} \mathrm{PD}-\mathrm{L} 1^{+} \mathrm{CD} 19^{+}$ Breg subset from 4T1-bearing mice exerted the greatest suppressive function on the proliferation and IFN- $\gamma$ production of $\mathrm{T}$ cell in an established B cell/T cell co-culture system (42). These results confirm the role of PD-1/PD-L1 as an immune checkpoint involved in the suppressive properties of Bregs in tumor models. Further studies could investigate whether PD $-1^{+} /$ $\mathrm{PD}-\mathrm{L1}^{+}$Bregs exert dominant suppressive functions in $\mathrm{HCC}$ or breast cancer. If so, then B-cell depletion might restore antitumor responses. In murine colorectal tumors, $\operatorname{IgA}^{+}$Bregs expressed high quantities of immunoregulatory molecules (PD-L1, IL-10, and TGF- $\beta$ ) and suppressed the proliferation and activation of $\mathrm{CD}^{+} \mathrm{T}$ cells (43). Moreover, the EMT- 6 murine mammary adenocarcinoma cells stimulated splenic B cells to differentiate into Bregs in vitro, which impaired the proliferation and IFN- $\gamma$ production of effector T cells (76).

\section{Enhancement of Treg Induction}

Aside from directly regulating effector $\mathrm{T}$ cell responses, Bregs also induce and promote Tregs to create an immunosuppressive microenvironment. In GC patients, Bregs upregulated Foxp3 expression in $\mathrm{CD}^{+} \mathrm{CD} 25^{-}$effector $\mathrm{T}$ cells in a TGF- $\beta 1$ dependent manner (37). Similarly, Bregs from IBCa patients induced more Treg production than did Bregs from healthy individuals in vitro (31). In terms of tongue squamous cell carcinoma (TSCC), Bregs co-cultured with a TSCC cell line converted $\mathrm{CD}^{+} \mathrm{CD} 25^{-} \mathrm{T}$ cells into Tregs (46). In a mouse $4 \mathrm{~T} 1$ model of breast cancer, tumor-evoked Bregs (tBregs) transformed resting $\mathrm{CD}^{+} \mathrm{T}$ cells into Foxp $3^{+}$Tregs by secreting TGF- $\beta$ to promote lung metastases (77). Moreover, Guan et al. found that PD-L1 ${ }^{\text {hi }}$ breast cancer cell lines stimulated CD $19^{+} \mathrm{B}$ cells to form Bregs, which subsequently induced Tregs in vitro (31). These studies revealed that both human and murine Bregs could induce Tregs in the TME, and the mechanism underlying these Treg induction requires further investigation to allow for possible disruption of the link between tumor Bregs and Tregs.

\section{Bregs and Myeloid-Derived Suppressor Cells (MDSCs)}

MDSCs are a group of immature cells that are potent in immune suppressors in cancer (83-85). The expansion of MDSCs has often been recognized as an indicator of tumor burden and metastasis $(86,87)$. However, Bodogai et al. observed that B-cell depletion significantly dampened the production of reactive oxygen species and NO by MDSCs as well as the suppressive effect of MDSCs on the proliferation and production of GrB and IFN- $\gamma$ of $\mathrm{CD}^{+} \mathrm{T}$ cells, while adoptive transfer of $\mathrm{tBregs}$ restored MDSC-mediated suppression of $\mathrm{T}$ cells in a B-cell-deficient mouse model, thus promoting cancer escape and metastasis (78). And experiment results are consistent in other tumor models and human cells. Their study demonstrates that tBregs educate MDSCs to fully evoke the regulatory and prometastatic functions of MDSCs, and cancer-stimulated expansion of MDSCs is not necessarily related to their regulatory functions.

\section{Other Tumor-Infiltrating Targets of Bregs}

Natural killer (NK) cells are critical effectors of the host innate immune system, and they can directly lyse pathogen-infected and injured cells (88). NK cells have been determined to participate in caner immunology $(89,90)$. Using a B-cell knockout mice model, Inoue and colleagues demonstrated that EL-4 gag tumor cells stimulated B cells to secrete IL-10, which in turn inhibited IFN $-\gamma$ production and tumor elimination by NK 
cells (60). In patients with hematological malignancies, bone marrow-derived Bregs abolished NK cell-mediated lysis of multiple myeloma (MM) cells in vitro (45). Regarding tumorinfiltrating B cells, Bregs from head and neck squamous cell carcinoma (HNSCC) patients produced adenosine to dampen the phosphorylation of Bruton's tyrosine kinase (BTK) and $\mathrm{Ca}^{2+}$ influx in effector B cells; thus adenosine signaling may be a possible therapeutic target in HNSCC (47). Until now, the effects of Bregs on tumor-infiltrating monocytes/macrophages remain mostly uninvestigated. In a lymphoma mouse model treated with anti-CD20 mAbs, Bregs produced IL-10 to suppress mAbmediated monocyte activation and effector function, resulting in reduced depletion of lymphoma cells (44).

\section{Cross-Regulation Between Bregs and Tumor Cells}

In addition to infiltrating immune cells, Bregs also directly interacted with liver cancer cells through the CD40/CD154 signaling pathway to enhance HCC growth and invasion (48), indicating that disruption of tumor-Breg interactions might be a potential therapeutic strategy to treat HCC. Moreover, Bregs adoptively transferred into B-cell-deficient mice rescued the growth of Kras-expressing pancreatic ductal epithelial cells by secreting IL-35, indicating the role of Bregs in carcinogenesis (91). Intriguingly, tumor cells also induce the generation of Bregs to suppress antitumor immunity. In MM patients, Breg survival was enhanced through MM cell-mediated inhibition of Breg apoptosis in the bone marrow (45). Similarly, breast cancer cells produced metabolites of the 5-lipoxygenase pathway to activate the peroxisome proliferator-activated receptor $\alpha$ (PPAR $\alpha)$ in B cells, resulting in tBreg generation; unsurprisingly, inactivation of PPAR $\alpha$ prevented tBreg-mediated cancer escape (79). In mice bearing B16-F10 melanoma, T2-MZP Bregs were specifically accumulated in TDLNs (32). Adoptive transfer of these Bregs into B-cell-deficient mice promoted tumor growth, which was not mediated by IL-10 secretion. A deeper understanding of the mechanisms underlying the preferential accumulation of T2MZP Bregs and promotion of tumors might benefit therapeutic strategies for cancer. The findings discussed above reveal that Bregs and tumors interact and regulate each other in the TME.

\section{POTENTIAL OF BREGS AS BIOMARKERS AND PROGNOSTIC FACTORS FOR CANCER}

Bregs have been confirmed to be associated with the clinicopathological characteristics of tumors and correlated with the prognosis of cancer patients (Table 3 ).

In TSCC, immunohistochemical staining of Bregs was performed on the paraffin-embedded tissue sections of 46 TSCC patients (46). The results showed that the percentage of Bregs was significantly correlated with clinical stage, local recurrence, and regional recurrence $(P<0.05)$. Moreover, Kaplan-Meier analysis showed that an increased Breg frequency predicted significantly worse overall survival (OS) of TSCC patients. Regarding hematological malignancy, Lv et al. investigated the effects of age, white blood cell (WBC) level and Breg frequency on the survival of acute myeloid leukemia (AML) patients (49). They found that an increased Breg percentage indicated a shorter OS for older patients or patients with high WBC levels. Additionally, the frequency of circulating Bregs was significantly correlated with FIGO stages, lymph node metastasis, tumor differentiation, human papillomavirus (HPV) infection, and the tumor metastasis of cervical cancer $(P<0.05)$, and this frequency decreased significantly after radical resection of cervical cancer (36). Thus, Bregs may also act as an indicator when evaluating cervical cancer development. Moreover, Yuki and colleagues divided GC patients into Breg ${ }^{\text {Low }}$ and Breg ${ }^{\text {High }}$ groups based on Breg frequencies in tumor tissue. Survival analysis showed that five-year OS rates in the Breg ${ }^{\text {Low }}$ group were significantly higher than those in the Breg ${ }^{\text {High }}$ group.

TABLE 3 | Clinical relevance of tumor-associated Bregs.

\begin{tabular}{|c|c|c|c|c|c|}
\hline Reference & $\begin{array}{l}\text { Breg } \\
\text { Types }\end{array}$ & $\begin{array}{l}\text { Cancer } \\
\text { Type }\end{array}$ & $\begin{array}{l}\text { Patient } \\
\text { Number }\end{array}$ & $\begin{array}{l}\text { Significant Correlation with } \\
\text { Clinicopathological Features }\end{array}$ & Prognostic Significance \\
\hline$(48)$ & $\begin{array}{l}\text { Circulating } \\
\text { Bregs }\end{array}$ & $\mathrm{HCC}$ & 74 & $\begin{array}{l}\text { Tumor UICC stages, tumor multiplicity and venous } \\
\text { infiltration }\end{array}$ & -- \\
\hline$(36)$ & $\begin{array}{l}\text { Circulating } \\
\text { Bregs }\end{array}$ & $\begin{array}{l}\text { Cervical } \\
\text { cancer }\end{array}$ & 70 & $\begin{array}{l}\text { FIGO stages, lymph node metastasis, tumor } \\
\text { differentiation, HPV infection and tumor metastasis }\end{array}$ & -- \\
\hline (39) & $\begin{array}{l}\text { Tumoral } \\
\text { Bregs }\end{array}$ & $\mathrm{HCC}$ & 51 & $\begin{array}{l}\text { TNM stage, microvascular invasion and early } \\
\text { recurrence }\end{array}$ & $\begin{array}{l}\text { Negatively correlated with DFS and OS of patients who } \\
\text { underwent curative surgical resection }\end{array}$ \\
\hline (46) & $\begin{array}{l}\text { Tumoral } \\
\text { Bregs }\end{array}$ & TSCC & 46 & $\begin{array}{l}\text { Correlated with clinical stage, local recurrence, and } \\
\text { regional recurrence }\end{array}$ & Negatively associated with OS of TSCC patients \\
\hline (49) & $\begin{array}{l}\text { Bregs in } \\
\text { PB and BM }\end{array}$ & AML & 46 & -- & $\begin{array}{l}\text { An increased Breg percentage indicated a shorter OS for older } \\
\text { patients or patients with high WBC levels. }\end{array}$ \\
\hline (50) & $\begin{array}{l}\text { Tumoral } \\
\text { Bregs }\end{array}$ & GC & 30 & -- & $\begin{array}{l}\text { Percentage of Bregs in tumor tissues was an independent } \\
\text { prognostic indicator of GC patient survival. }\end{array}$ \\
\hline$(40)$ & $\begin{array}{l}\text { Tumor } \\
\text { Bregs }\end{array}$ & $\mathrm{HCC}$ & 43 & -- & $\begin{array}{l}\text { Frequencies of PD- } 1^{\text {hi }} \text { Bregs in tumor tissues were significantly } \\
\text { correlated with disease progression in patients. }\end{array}$ \\
\hline
\end{tabular}

Breg, regulatory B cell; HCC, hepatocellular carcinoma; UICC, Union for International Cancer Control; FIGO, International Federation of Gynecology and Obstetrics; HPV, human papillomavirus; DFS, disease-free survival; OS, overall survival; TSCC, tongue squamous cell carcinoma; AML, acute myeloid leukemia; WBC, white blood cell; GC, gastric cancer; PB, peripheral blood; BM, bone marrow. 
Multivariate analysis revealed that the percentage of Bregs in tumor tissue was an independent prognostic indicator of GC patient survival (50). This study indicates that Breg-related immunosuppression is closely correlated to tumor progression. In clinics, disseminated micrometastases overlooked by ordinary diagnostics are a likely reason for tumor recurrence. We propose that sustained Breg-mediated immunosuppression creates an ideal environment for residual cancer cells to grow and develop, eventually leading to recurrence.

In HCC patients, the frequency of TIM- $1^{+}$Bregs in the tumor tissue was positively associated with patient TNM stage, microvascular invasion and early recurrence. Additionally, Kaplan-Meier analysis verified that the density of tumorinfiltrating TIM- $1^{+}$Bregs was negatively correlated with disease-free survival (DFS) $(\mathrm{n}=101, P=0.018)$ and $\mathrm{OS}(\mathrm{n}=$ 101, $P=0.007$ ) of patients who underwent curative surgical resection (39). The results suggest that TIM- $1^{+}$Bregs could serve as a potential indicator when evaluating tumor progression and making clinical decisions in HCC. In another study by Shao et al., peripheral blood samples from 21 normal individuals and 74 HCC patients who underwent hepatectomy were examined (48). The results showed that the frequency of circulating Bregs was significantly correlated with tumor UICC stages $(P=0.019)$, tumor multiplicity $(P=0.023)$ and venous infiltration $(P=0.029)$. Therefore, during the postoperative period, the dynamics of circulating Bregs in HCC patients might be a potential predictor of tumor recurrence. Furthermore, Xiao and colleagues observed that in HCC, the frequencies of PD- ${ }^{\text {hi }}$ Bregs in tumor tissues were significantly associated with disease progression in patients, and 2.6 times more patients with higher frequencies of PD-1 ${ }^{\text {hi }}$ Bregs displayed early recurrence than those with lower frequencies (40). Interestingly, another study demonstrated that HCC patients with high proportions of tumor-infiltrating $\mathrm{B}$ cells showed better prognosis compared with those with low proportions (92), indicating that the existence of B-cell subsets with antitumor functions in tumor tissues. Considering the antitumorigenic and protumorigenic properties of $\mathrm{B}$ cells in the TME, we believe that the distribution and subset arrangement of B cells underpin their distinct functions in specific intratumor regions.

\section{THERAPEUTIC BREG-TARGETING STRATEGIES FOR CANCER TREATMENT}

As Bregs generally exert immunosuppressive and protumorigenic functions, it is noteworthy that Bregs could be potential therapeutic targets of cancer. Several preclinical studies have targeted Bregs in various cancer models. Mitogen/extracellular signal regulated kinase (MEK) is an intermediary component of the mitogen-activated protein kinase (MAPK) pathway. MEK inhibition has shown effects on tumors with MAPK activation both alone and in combination with other targeted therapies (9395). In a colorectal cancer model in vivo, cobimetinib, a MEK inhibitor, decreased the number of Bregs in TDLNs while sparing anti-tumor humoral immunity (96). Mechanistically, MEK inhibition might reduce Bregs through the interruption of chronic BCR signaling, thus impairing the upregulation of specific suppressive surface molecules. Regarding HCC, total glucoside of paeony (TGP), which is extracted from the root of Paeonia Lactiflora, decreased the proportion of B10 cells in the spleens of experimental rats, which at least partially contributed to the anti tumor effect of TGP on rat HCC (97). In addition, lipoxin A4 (LXA4) is an arachidonic acid-derived anti-inflammatory lipid mediator that possesses anti-tumor potential through modulating tumor-immune microenvironments. In tumor-bearing mice, LXA4 suppressed Breg induction, thereby reducing Tregs in draining lymph nodes and tumor tissues as well as augmenting cytotoxic T cell activities (98). Intriguingly, LXA4 targeted Bregs selectively and didn't affect the proliferation, differentiation and germinal center formation of conventional B cells. Moreover, resveratrol, a plant-derived phytoalexin, inhibits tumor angiogenesis and is a potential anticancer therapeutic drug (99). In mice with highly metastatic mammary $4 \mathrm{~T} 1.2$ adenocarcinoma, noncytotoxic low doses of resveratrol preferentially dampened tBreg generation and concurrently impaired the tBreg-induced conversion of Foxp $3^{+}$Tregs to block lung metastasis (51). In pancreatic ductal adenocarcinoma, $\mathrm{CD} 1 \mathrm{~d}^{\text {hi }} \mathrm{CD} 5^{+}$Bregs exert protumorigenic functions by promoting tumor cell proliferation. Shipra Das and colleagues identified BTK as a vital modulator of $\mathrm{CD} 1 \mathrm{~d}^{\text {hi }} \mathrm{CD}^{+}$Breg differentiation and immunosuppressive function (52). The BTK inhibitor tirabrutinib suppressed CD1d ${ }^{\text {hi }} \mathrm{CD}^{+}$Breg differentiation as well as IL-10 and IL-35 secretion in vitro. Moreover, tirabrutinib treatment of mice bearing orthotopic Kras ${ }^{\mathrm{G} 12 \mathrm{D}}$-pancreatic lesions increased stromal CD ${ }^{+}$IFN $-\gamma^{+}$cytotoxic $\mathrm{T}$ cells and attenuated tumor cell proliferation and pancreatic intra-epithelial neoplasia (PanIN) growth. Thus, Bregs may be potential targets of tirabrutinib in PanIN. These studies have confirmed the practicability of inhibiting Bregs to suppress cancer progression. Further investigations are needed to develop a Breg-targeting therapeutic regimen for cancer.

\section{CHALLENGES AND FUTURE IMPLICATIONS}

Despite accumulating evidence corroborating the immunoregulatory functions of Bregs in tumor immunology, there are still few unequivocal surface markers for Bregs. Unlike Foxp3 on Tregs, a specific transcriptional factor for identifying Bregs has not been found. One reason for the differences in reported Breg phenotypes may be the various methods utilized to isolate Bregs. It is debatable whether immunoregulatory functions are innate and whether Bregs and their specific signatures are only the results of the adaptation of $B$ cells to different TME stimuli. Lighaam and colleagues reported that in vitro-induced human $\mathrm{B} 10$ cells lacked specific surface markers, and their IL-10 expression was transient (100). Therefore, the intricate mechanism underlying Breg induction and function during cancer progression needs to be further explicated.

In summary, Bregs have been widely recognized as a subset of $B$ cells that regulate inflammation and antitumor responses. 
Generally, Bregs exert their functions mainly through cytokine secretion and intercellular contact. In the TME, Bregs suppress effector $\mathrm{T}$ cells, induce regulatory $\mathrm{T}$ cells and target other tumorinfiltrating immune cells, such as MDSCs, NK cells, and macrophages, to hamper anti-tumor immunity. Meanwhile, the cross-regulations between Bregs and tumor cells often results in tumor escape from immunosurveillance. In addition, Bregs are closely associated with many clinicopathological factors of cancer patients and might predict patient survival. It is imperative that subsequent efforts focus on identifying unique surface markers of Bregs and developing Bregs as potential targets for future Breg-based immunotherapies.

\section{REFERENCES}

1. Meffre E, O'Connor KC. Impaired B-cell tolerance checkpoints promote the development of autoimmune diseases and pathogenic autoantibodies. Immunol $\operatorname{Rev}(2019)$ 292(1):90-101. doi: 10.1111/imr.12821

2. LeBien TW, Tedder TF. B lymphocytes: how they develop and function. Blood (2008) 112(5):1570-80. doi: 10.1182/blood-2008-02-078071

3. Luman Wang YF, Chu Y. "Regulatory B Cells". In: J Wang, editor. B cells in immunity and tolerance Advances in Experimental Medicine and Biology. Singapore: Springer (2020). p. 87-103.

4. Sprenger KG, Louveau JE, Murugan PM, Chakraborty AK. Optimizing immunization protocols to elicit broadly neutralizing antibodies. Proc Natl Acad Sci U S A (2020) 117(33):20077-87. doi: 10.1073/pnas.1919329117

5. Joyner CJ, Brito CFA, Saney CL, Joice Cordy R, Smith ML, Lapp SA, et al. Humoral immunity prevents clinical malaria during Plasmodium relapses without eliminating gametocytes. PLoS Path (2019) 15(9):e1007974. doi: 10.1371/journal.ppat.1007974

6. Smith SA, Burton SL, Kilembe W, Lakhi S, Karita E, Price M, et al. VH1-69 Utilizing Antibodies Are Capable of Mediating Non-neutralizing Fc-Mediated Effector Functions Against the Transmitted/Founder gp120. Front Immunol (2018) 9:3163. doi: 10.3389/fimmu.2018.03163

7. Kim HS, Lee MB, Lee D, Min KY, Koo J, Kim HW, et al. The regulatory B cellmediated peripheral tolerance maintained by mast cell IL-5 suppresses oxazolone-induced contact hypersensitivity. Sci Adv (2019) 5(7):eaav8152. doi: $10.1126 /$ sciadv.aav8152

8. Korniotis S, Gras C, Letscher H, Montandon R, Megret J, Siegert S, et al. Treatment of ongoing autoimmune encephalomyelitis with activated B-cell progenitors maturing into regulatory B cells. Nat Commun (2016) 7:12134. doi: $10.1038 /$ ncomms 12134

9. Kalampokis I, Venturi GM, Poe JC, Dvergsten JA, Sleasman JW, Tedder TF. The Regulatory B Cell Compartment Expands Transiently During Childhood and Is Contracted in Children With Autoimmunity. Arthritis Rheumatol (2017) 69(1):225-38. doi: 10.1002/art.39820

10. Giacomini E, Rizzo F, Etna MP, Cruciani M, Mechelli R, Buscarinu MC, et al. Thymosin-alphal expands deficient IL-10-producing regulatory B cell subsets in relapsing-remitting multiple sclerosis patients. Mult Scler (2018) 24(2):12739. doi: $10.1177 / 1352458517695892$

11. Katz SI, Parker D, Turk JL. B-cell suppression of delayed hypersensitivity reactions. Nature (1974) 251(5475):550-1. doi: 10.1038/251550a0

12. Neta R, Salvin SB. Specific suppression of delayed hypersensitivity: the possible presence of a suppressor B cell in the regulation of delayed hypersensitivity. J Immunol (1974) 113(6):1716-25.

13. Shimamura T, Hashimoto K, Sasaki S. Feedback suppression of the immune response in vivo. III. Lyt-1+B cells are suppressor-inducer cells. Cell Immunol (1982) 68(1):104-13. doi: 10.1016/0008-8749(82)90093-4

14. Shimamura T, Habu S, Hashimoto K, Sasaki S. Feedback suppression of the immune response in vivo. III. Lyt-1+B Cells are suppressor-inducer Cells Cell Immunol (1984) 83(1):221-4. doi: 10.1016/0008-8749(84)90242-9

15. Mizoguchi A, Mizoguchi E, Takedatsu H, Blumberg RS, Bhan AK. Chronic intestinal inflammatory condition generates IL-10-producing regulatory B cell

\section{AUTHOR CONTRIBUTIONS}

JS and HZ prepared the first draft of the manuscript. YS designed and critically revised the manuscript. All authors contributed to the article and approved the submitted version.

\section{FUNDING}

This work was supported by the National Natural Science Foundation of China under Grant [number 31900627].

subset characterized by CD1d upregulation. Immunity (2002) 16(2):219-30. doi: 10.1016/s1074-7613(02)00274-1

16. Zhivaki D, Lemoine S, Lim A, Morva A, Vidalain PO, Schandene L, et al. Respiratory Syncytial Virus Infects Regulatory B Cells in Human Neonates via Chemokine Receptor CX3CR1 and Promotes Lung Disease Severity. Immunity (2017) 46(2):301-14. doi: 10.1016/j.immuni. 2017.01.010

17. van de Veen W, Stanic B, Wirz OF, Jansen K, Globinska A, Akdis M. Role of regulatory $\mathrm{B}$ cells in immune tolerance to allergens and beyond. J Allergy Clin Immunol (2016) 138(3):654-65. doi: 10.1016/j.jaci.2016.07.006

18. Kim Y, Kim G, Shin HJ, Hyun JW, Kim SH, Lee E, et al. Restoration of regulatory B cell deficiency following alemtuzumab therapy in patients with relapsing multiple sclerosis. J Neuroinflamm (2018) 15(1):300. doi: 10.1186/ s12974-018-1334-y

19. Peng B, Ming Y, Yang C. Regulatory B cells: the cutting edge of immune tolerance in kidney transplantation. Cell Death Dis (2018) 9(2):109. doi: 10.1038/s41419-017-0152-y

20. Baba Y, Saito Y, Kotetsu Y. Heterogeneous subsets of B-lineage regulatory cells (Breg cells). Int Immunol (2020) 32(3):155-62. doi: 10.1093/intimm/dxz068

21. Sarvaria A, Madrigal JA, Saudemont A. B cell regulation in cancer and antitumor immunity. Cell Mol Immunol (2017) 14(8):662-74. doi: 10.1038/ cmi.2017.35

22. Zhang Y, Gallastegui N, Rosenblatt JD. Regulatory B cells in anti-tumor immunity. Int Immunol (2015) 27(10):521-30. doi: 10.1093/intimm/dxv034

23. Cai X, Zhang L, Wei W. Regulatory B cells in inflammatory diseases and tumor. Int Immunopharmacol (2019) 67:281-6. doi: 10.1016/ j.intimp.2018.12.007

24. He Y, Qian H, Liu Y, Duan L, Li Y, Shi G. The roles of regulatory B cells in cancer. J Immunol Res (2014) 2014:215471. doi: 10.1155/2014/215471

25. Balkwill F, Montfort A, Capasso M. B regulatory cells in cancer. Trends Immunol (2013) 34(4):169-73. doi: 10.1016/j.it.2012.10.007

26. Dzopalic T, Bozic-Nedeljkovic B, Jurisic V. Function of innate lymphoid cells in the immune-related disorders. Hum Cell (2019) 32(3):231-9. doi: 10.1007/ s13577-019-00257-1

27. Rosser EC, Mauri C. Regulatory B cells: origin, phenotype, and function. Immunity (2015) 42(4):607-12. doi: 10.1016/j.immuni.2015.04.005

28. Kessel A, Haj T, Peri R, Snir A, Melamed D, Sabo E, et al. Human CD19(+) $\mathrm{CD} 25$ (high) $\mathrm{B}$ regulatory cells suppress proliferation of CD4(+) $\mathrm{T}$ cells and enhance Foxp3 and CTLA-4 expression in T-regulatory cells. Autoimmun Rev (2012) 11(9):670-7. doi: 10.1016/j.autrev.2011.11.018

29. Li G, Wulan H, Song Z, Paik PA, Tsao ML, Goodman GM, et al. Regulatory B Cell Function Is Suppressed by Smoking and Obesity in H. pylori-Infected Subjects and Is Correlated with Elevated Risk of Gastric Cancer. PLoS One (2015) 10(7):e0134591. doi: 10.1371/journal.pone.0134591

30. Lindner S, Dahlke K, Sontheimer K, Hagn M, Kaltenmeier C, Barth TF, et al. Interleukin 21-induced granzyme B-expressing B cells infiltrate tumors and regulate T cells. Cancer Res (2013) 73(8):2468-79. doi: 10.1158/00085472.CAN-12-3450

31. Guan H, Lan Y, Wan Y, Wang Q, Wang C, Xu L, et al. PD-L1 mediated the differentiation of tumor-infiltrating CD19(+) B lymphocytes and T cells in 
Invasive breast cancer. OncoImmunology (2016) 5(2):e1075112. doi: 10.1080/ 2162402X.2015.1075112

32. Ganti SN, Albershardt TC, Iritani BM, Ruddell A. Regulatory B cells preferentially accumulate in tumor-draining lymph nodes and promote tumor growth. Sci Rep (2015) 5:12255. doi: 10.1038/srep12255

33. Yanaba K, Bouaziz JD, Haas KM, Poe JC, Fujimoto M, Tedder TF. A regulatory $\mathrm{B}$ cell subset with a unique $\mathrm{CD} 1 \mathrm{dhiCD} 5+$ phenotype controls $\mathrm{T}$ cell-dependent inflammatory responses. Immunity (2008) 28(5):639-50. doi: 10.1016/j.immuni.2008.03.017

34. Maseda D, Smith SH, DiLillo DJ, Bryant JM, Candando KM, Weaver CT, et al. Regulatory B10 cells differentiate into antibody-secreting cells after transient IL-10 production in vivo. J Immunol (2012) 188(3):1036-48. doi: 10.4049/ jimmunol.1102500

35. Kaku H, Cheng KF, Al-Abed Y, Rothstein TL. A novel mechanism of B cellmediated immune suppression through $\mathrm{CD} 73$ expression and adenosine production. J Immunol (2014) 193(12):5904-13. doi: 10.4049/ jimmunol.1400336

36. Chen Z, Zhu Y, Du R, Pang N, Zhang F, Dong D, et al. Role of Regulatory B Cells in the Progression of Cervical Cancer. Mediators Inflamm (2019) 2019:6519427. doi: 10.1155/2019/6519427

37. Wang WW, Yuan XL, Chen H, Xie GH, Ma YH, Zheng YX, et al. CD19 $+\mathrm{CD} 24 \mathrm{hiCD} 38 \mathrm{hiBregs}$ involved in downregulate helper T cells and upregulate regulatory $\mathrm{T}$ cells in gastric cancer. Oncotarget (2015) 6(32):33486-99. doi: 10.18632/oncotarget.5588

38. Hu HT, Ai X, Lu M, Song Z, Li H. Characterization of intratumoral and circulating IL-10-producing B cells in gastric cancer. Exp Cell Res (2019) 384 (2):111652. doi: 10.1016/j.yexcr.2019.111652

39. Ye L, Zhang Q, Cheng Y, Chen X, Wang G, Shi M, et al. Tumor-derived exosomal HMGB1 fosters hepatocellular carcinoma immune evasion by promoting TIM-1(+) regulatory B cell expansion. J Immunother Cancer (2018) 6(1):145. doi: 10.1186/s40425-018-0451-6

40. Xiao X, Lao XM, Chen MM, Liu RX, Wei Y, Ouyang FZ, et al. PD-1hi Identifies a Novel Regulatory B-cell Population in Human Hepatoma That Promotes Disease Progression. Cancer Discov (2016) 6(5):546-59. doi: 10.1158/2159-8290.CD-15-1408

41. Wu H, Xia L, Jia D, Zou H, Jin G, Qian W, et al. PD-L1(+) regulatory B cells act as a $\mathrm{T}$ cell suppressor in a PD-L1-dependent manner in melanoma patients with bone metastasis. Mol Immunol (2020) 119:83-91. doi: 10.1016/ j.molimm.2020.01.008

42. Shen M, Wang J, Yu W, Zhang C, Liu M, Wang K, et al. A novel MDSCinduced PD-1(-)PD-L1(+) B-cell subset in breast tumor microenvironment possesses immuno-suppressive properties. OncoImmunology (2018) 7(4): e1413520. doi: 10.1080/2162402X.2017.1413520

43. Liu R, Lu Z, Gu J, Liu J, Huang E, Liu X, et al. MicroRNAs 15A and 16-1 Activate Signaling Pathways That Mediate Chemotaxis of Immune Regulatory B cells to Colorectal Tumors. Gastroenterology (2018) 154(3):637-51 e7. doi: 10.1053/j.gastro.2017.09.045

44. Horikawa M, Minard-Colin V, Matsushita T, Tedder TF. Regulatory B cell production of IL-10 inhibits lymphoma depletion during CD20 immunotherapy in mice. J Clin Invest (2011) 121(11):4268-80. doi: 10.1172/JCI59266

45. Zhang L, Tai YT, Ho M, Xing L, Chauhan D, Gang A, et al. Regulatory B cellmyeloma cell interaction confers immunosuppression and promotes their survival in the bone marrow milieu. Blood Cancer J (2017) 7(3):e547. doi: $10.1038 /$ bcj.2017.24

46. Zhou X, Su YX, Lao XM, Liang YJ, Liao GQ. CD19(+)IL-10(+) regulatory B cells affect survival of tongue squamous cell carcinoma patients and induce resting CD4(+) T cells to $\mathrm{CD} 4(+)$ Foxp3(+) regulatory $\mathrm{T}$ cells. Oral Oncol (2016) 53:27-35. doi: 10.1016/j.oraloncology.2015.11.003

47. Jeske SS, Brand M, Ziebart A, Laban S, Doescher J, Greve J, et al. Adenosineproducing regulatory B cells in head and neck cancer. Cancer Immunol Immunother (2020) 69(7):1205-16. doi: 10.1007/s00262-020-02535-6

48. Shao Y, Lo CM, Ling CC, Liu XB, Ng KT, Chu AC, et al. Regulatory B cells accelerate hepatocellular carcinoma progression via CD40/CD154 signaling pathway. Cancer Lett (2014) 355(2):264-72. doi: 10.1016/j.canlet.2014.09.026

49. Lv Y, Wang H, Liu Z. The Role of Regulatory B Cells in Patients with Acute Myeloid Leukemia. Med Sci Monit (2019) 25:3026-31. doi: 10.12659/ MSM.915556
50. Murakami Y, Saito H, Shimizu S, Kono Y, Shishido Y, Miyatani K, et al. Increased regulatory B cells are involved in immune evasion in patients with gastric cancer. Sci Rep (2019) 9(1):13083. doi: 10.1038/s41598-019-49581-4

51. Lee-Chang C, Bodogai M, Martin-Montalvo A, Wejksza K, Sanghvi M, Moaddel $\mathrm{R}$, et al. Inhibition of breast cancer metastasis by resveratrolmediated inactivation of tumor-evoked regulatory B cells. J Immunol (2013) 191(8):4141-51. doi: 10.4049/jimmunol.1300606

52. Das S, Bar-Sagi D. BTK signaling drives CD1d(hi)CD5(+) regulatory B-cell differentiation to promote pancreatic carcinogenesis. Oncogene (2019) 38 (17):3316-24. doi: 10.1038/s41388-018-0668-3

53. Mao H, Pan F, Wu Z, Wang Z, Zhou Y, Zhang P, et al. Colorectal tumors are enriched with regulatory plasmablasts with capacity in suppressing $\mathrm{T}$ cell inflammation. Int Immunopharmacol (2017) 49:95-101. doi: 10.1016/ j.intimp.2017.05.018

54. Akdis M, Aab A, Altunbulakli C, Azkur K, Costa RA, Crameri R, et al. Interleukins (from IL-1 to IL-38), interferons, transforming growth factor beta, and TNF-alpha: Receptors, functions, and roles in diseases. J Allergy Clin Immunol (2016) 138(4):984-1010. doi: 10.1016/j.jaci.2016.06.033

55. Khoder A, Sarvaria A, Alsuliman A, Chew C, Sekine T, Cooper N, et al. Regulatory B cells are enriched within the IgM memory and transitional subsets in healthy donors but are deficient in chronic GVHD. Blood (2014) 124(13):2034-45. doi: 10.1182/blood-2014-04-571125

56. Cerqueira C, Manfroi B, Fillatreau S. IL-10-producing regulatory B cells and plasmocytes: Molecular mechanisms and disease relevance. Semin Immunol (2019) 44:101323. doi: 10.1016/j.smim.2019.101323

57. Wu H, Su Z, Barnie PA. The role of B regulatory (B10) cells in inflammatory disorders and their potential as therapeutic targets. Int Immunopharmacol (2020) 78:106111. doi: 10.1016/j.intimp.2019.106111

58. Das A, Ellis G, Pallant C, Lopes AR, Khanna P, Peppa D, et al. IL-10producing regulatory $\mathrm{B}$ cells in the pathogenesis of chronic hepatitis $\mathrm{B}$ virus infection. J Immunol (2012) 189(8):3925-35. doi: 10.4049/jimmunol.1103139

59. Madan R, Demircik F, Surianarayanan S, Allen JL, Divanovic S, Trompette A, et al. Nonredundant roles for B cell-derived IL-10 in immune counterregulation. J Immunol (2009) 183(4):2312-20. doi: 10.4049/ jimmunol.0900185

60. Inoue S, Leitner WW, Golding B, Scott D. Inhibitory effects of B cells on antitumor immunity. Cancer Res (2006) 66(15):7741-7. doi: 10.1158/00085472.CAN-05-3766

61. Butz H, Racz K, Hunyady L, Patocs A. Crosstalk between TGF-beta signaling and the microRNA machinery. Trends Pharmacol Sci (2012) 33(7):382-93. doi: 10.1016/j.tips.2012.04.003

62. Tian J, Zekzer D, Hanssen L, Lu Y, Olcott A, Kaufman DL. Lipopolysaccharide-activated B cells down-regulate Th1 immunity and prevent autoimmune diabetes in nonobese diabetic mice. J Immunol (2001) 167(2):1081-9. doi: 10.4049/jimmunol.167.2.1081

63. Shen P, Roch T, Lampropoulou V, O'Connor RA, Stervbo U, Hilgenberg E, et al. IL-35-producing B cells are critical regulators of immunity during autoimmune and infectious diseases. Nature (2014) 507(7492):366-70. doi: 10.1038/nature12979

64. Egwuagu CE, Yu CR, Sun L, Wang R. Interleukin 35: Critical regulator of immunity and lymphocyte-mediated diseases. Cytokine Growth Factor Rev (2015) 26(5):587-93. doi: 10.1016/j.cytogfr.2015.07.013

65. Tang Q, Bluestone JA. The Foxp3+ regulatory $\mathrm{T}$ cell: a jack of all trades, master of regulation. Nat Immunol (2008) 9(3):239-44. doi: 10.1038/ni1572

66. Blair PA, Norena LY, Flores-Borja F, Rawlings DJ, Isenberg DA, Ehrenstein MR, et al. CD19(+)CD24(hi)CD38(hi) B cells exhibit regulatory capacity in healthy individuals but are functionally impaired in systemic Lupus Erythematosus patients. Immunity (2010) 32(1):129-40. doi: 10.1016/ j.immuni.2009.11.009

67. Flores-Borja F, Bosma A, Ng D, Reddy V, Ehrenstein MR, Isenberg DA, et al. CD19+CD24hiCD38hi B cells maintain regulatory T cells while limiting TH1 and TH17 differentiation. Sci Transl Med (2013) 5(173):173ra23. doi: 10.1126/ scitranslmed.3005407

68. Elgueta R, Benson MJ, de Vries VC, Wasiuk A, Guo Y, Noelle RJ. Molecular mechanism and function of CD40/CD40L engagement in the immune system. Immunol Rev (2009) 229(1):152-72. doi: 10.1111/j.1600-065X.2009.00782.X

69. Mauri C, Ehrenstein MR. The 'short' history of regulatory B cells. Trends Immunol (2008) 29(1):34-40. doi: 10.1016/j.it.2007.10.004 
70. Podolsky MA, Bailey JT, Gunderson AJ, Oakes CJ, Breech K, Glick AB. Differentiated State of Initiating Tumor Cells Is Key to Distinctive Immune Responses Seen in H-Ras(G12V)-Induced Squamous Tumors. Cancer Immunol Res (2017) 5(3):198-210. doi: 10.1158/2326-6066.CIR-16-0304

71. Hahne M, Renno T, Schroeter M, Irmler M, French L, Bornard T, et al. Activated B cells express functional Fas ligand. Eur J Immunol (1996) 26 (3):721-4. doi: 10.1002/eji.1830260332

72. Lundy SK, Boros DL. Fas ligand-expressing B-1a lymphocytes mediate CD4 (+)-T-cell apoptosis during schistosomal infection: induction by interleukin 4 (IL-4) and IL-10. Infect Immun (2002) 70(2):812-9. doi: 10.1128/iai.70.2.812819.2002

73. Wang K, Tao L, Su J, Zhang Y, Zou B, Wang Y, et al. TLR4 supports the expansion of FasL(+)CD5(+)CD1d(hi) regulatory B cells, which decreases in contact hypersensitivity. Mol Immunol (2017) 87:188-99. doi: 10.1016/ j.molimm.2017.04.016

74. Burgueno-Bucio E, Mier-Aguilar CA, Soldevila G. The multiple faces of CD5. J Leukocyte Biol (2019) 105(5):891-904. doi: 10.1002/JLB.MR0618-226R

75. Zhang C, Xin H, Zhang W, Yazaki PJ, Zhang Z, Le K, et al. CD5 Binds to Interleukin-6 and Induces a Feed-Forward Loop with the Transcription Factor STAT3 in B Cells to Promote Cancer. Immunity (2016) 44(4):91323. doi: 10.1016/j.immuni.2016.04.003

76. Zhang Y, Morgan R, Chen C, Cai Y, Clark E, Khan WN, et al. Mammarytumor-educated B cells acquire LAP/TGF-beta and PD-L1 expression and suppress anti-tumor immune responses. Int Immunol (2016) 28(9):423-33. doi: 10.1093/intimm/dxw007

77. Wei X, Jin Y, Tian Y, Zhang H, Wu J, Lu W, et al. Regulatory B cells contribute to the impaired antitumor immunity in ovarian cancer patients. Tumour Biol (2016) 37(5):6581-8. doi: 10.1007/s13277-015-4538-0

78. Han S, Feng S, Ren M, Ma E, Wang X, Xu L, et al. Glioma cell-derived placental growth factor induces regulatory B cells. Int J Biochem Cell Biol (2014) 57:63-8. doi: 10.1016/j.biocel.2014.10.005

79. Lee-Chang C, Rashidi A, Miska J, Zhang P, Pituch KC, Hou D, et al. MyeloidDerived Suppressive Cells Promote B cell-Mediated Immunosuppression via Transfer of PD-L1 in Glioblastoma. Cancer Immunol Res (2019) 7(12):192843. doi: 10.1158/2326-6066.CIR-19-0240

80. Olkhanud PB, Damdinsuren B, Bodogai M, Gress RE, Sen R, Wejksza K, et al. Tumor-evoked regulatory $\mathrm{B}$ cells promote breast cancer metastasis by converting resting CD4(+) T cells to T-regulatory cells. Cancer Res (2011) 71(10):3505-15. doi: 10.1158/0008-5472.CAN-10-4316

81. Bodogai M, Moritoh K, Lee-Chang C, Hollander CM, Sherman-Baust CA, Wersto RP, et al. Immunosuppressive and Prometastatic Functions of Myeloid-Derived Suppressive Cells Rely upon Education from TumorAssociated B Cells. Cancer Res (2015) 75(17):3456-65. doi: 10.1158/00085472.CAN-14-3077

82. Wejksza K, Lee-Chang C, Bodogai M, Bonzo J, Gonzalez FJ, Lehrmann E, et al. Cancer-produced metabolites of 5-lipoxygenase induce tumor-evoked regulatory B cells via peroxisome proliferator-activated receptor alpha. J Immunol (2013) 190(6):2575-84. doi: 10.4049/jimmunol.1201920

83. De Cicco P, Ercolano G, Ianaro A. The New Era of Cancer Immunotherapy: Targeting Myeloid-Derived Suppressor Cells to Overcome Immune Evasion. Front Immunol (2020) 11:1680. doi: 10.3389/fimmu.2020.01680

84. Sieminska I, Baran J. Myeloid-Derived Suppressor Cells in Colorectal Cancer. Front Immunol (2020) 11:1526. doi: 10.3389/fimmu.2020.01526

85. Jayakumar A, Bothwell ALM. Functional Diversity of Myeloid-Derived Suppressor Cells: The Multitasking Hydra of Cancer. J Immunol (2019) 203 (5):1095-103. doi: 10.4049/jimmunol.1900500

86. Gabrilovich DI, Nagaraj S. Myeloid-derived suppressor cells as regulators of the immune system. Nat Rev Immunol (2009) 9(3):162-74. doi: 10.1038/ nri2506
87. Bunt SK, Sinha P, Clements VK, Leips J, Ostrand-Rosenberg S. Inflammation induces myeloid-derived suppressor cells that facilitate tumor progression. J Immunol (2006) 176(1):284-90. doi: 10.4049/jimmunol.176.1.284

88. Vladimir J AV, Katarina MM, Gordana K. "The Role of NK Cells in Cancer" In: N Rezaei, editor. Cancer Immunology. Switzerland: Springer, Cham (2020). p. 133-46.

89. Konjevic GM, Vuletic AM, Mirjacic Martinovic KM, Larsen AK, Jurisic VB. The role of cytokines in the regulation of NK cells in the tumor environment. Cytokine (2019) 117:30-40. doi: 10.1016/j.cyto.2019.02.001

90. Bi J, Wang X. Molecular Regulation of NK Cell Maturation. Front Immunol (2020) 11:1945. doi: 10.3389/fimmu.2020.01945

91. Pylayeva-Gupta Y, Das S, Handler JS, Hajdu CH, Coffre M, Koralov SB, et al. IL35-Producing B Cells Promote the Development of Pancreatic Neoplasia. Cancer Discov (2016) 6(3):247-55. doi: 10.1158/2159-8290.CD-15-0843

92. Garnelo M, Tan A, Her Z, Yeong J, Lim CJ, Chen J, et al. Interaction between tumour-infiltrating $\mathrm{B}$ cells and $\mathrm{T}$ cells controls the progression of hepatocellular carcinoma. Gut (2017) 66(2):342-51. doi: 10.1136/gutjnl2015-310814

93. Caunt CJ, Sale MJ, Smith PD, Cook SJ. MEK1 and MEK2 inhibitors and cancer therapy: the long and winding road. Nat Rev Cancer (2015) 15 (10):577-92. doi: 10.1038/nrc4000

94. Robert C, Karaszewska B, Schachter J, Rutkowski P, Mackiewicz A, Stroiakovski D, et al. Improved overall survival in melanoma with combined dabrafenib and trametinib. N Engl J Med (2015) 372(1):30-9. doi: 10.1056/NEJMoa1412690

95. Larkin J, Ascierto PA, Dreno B, Atkinson V, Liszkay G, Maio M, et al. Combined vemurafenib and cobimetinib in BRAF-mutated melanoma. $N$ Engl J Med (2014) 371(20):1867-76. doi: 10.1056/NEJMoa1408868

96. Yarchoan M, Mohan AA, Dennison L, Vithayathil T, Ruggieri A, Lesinski GB, et al. MEK inhibition suppresses B regulatory cells and augments anti-tumor immunity. PLoS One (2019) 14(10):e0224600. doi: 10.1371/journal.pone. 0224600

97. Song SS, Yuan PF, Li PP, Wu HX, Ni WJ, Lu JT, et al. Protective Effects of Total Glucosides of Paeony on N-nitrosodiethylamine-induced Hepatocellular Carcinoma in Rats via Down-regulation of Regulatory B Cells. Immunol Invest (2015) 44(6):521-35. doi: 10.3109/08820139.2015.1043668

98. Wang Z, Cheng Q, Tang K, Sun Y, Zhang K, Zhang Y, et al. Lipid mediator lipoxin A4 inhibits tumor growth by targeting IL-10-producing regulatory B (Breg) cells. Cancer Lett (2015) 364(2):118-24. doi: 10.1016/j.canlet.2015. 04.030

99. Athar M, Back JH, Kopelovich L, Bickers DR, Kim AL. Multiple molecular targets of resveratrol: Anti-carcinogenic mechanisms. Arch Biochem Biophys (2009) 486(2):95-102. doi: 10.1016/j.abb.2009.01.018

100. Lighaam LC, Unger PA, Vredevoogd DW, Verhoeven D, Vermeulen E, Turksma AW, et al. In vitro-Induced Human IL-10(+) B Cells Do Not Show a Subset-Defining Marker Signature and Plastically Co-express IL-10 With Pro-Inflammatory Cytokines. Front Immunol (2018) 9:1913. doi: 10.3389/ fimmu.2018.01913

Conflict of Interest: The authors declare that the research was conducted in the absence of any commercial or financial relationships that could be construed as a potential conflict of interest.

Copyright (c) 2020 Shang, Zha and Sun. This is an open-access article distributed under the terms of the Creative Commons Attribution License (CC BY). The use, distribution or reproduction in other forums is permitted, provided the original author(s) and the copyright owner(s) are credited and that the original publication in this journal is cited, in accordance with accepted academic practice. No use, distribution or reproduction is permitted which does not comply with these terms. 